\title{
VILLAAMIL NO TIENE QUIEN LO NOMBRE Y EL CORONEL NO TIENE QUIEN LE ESCRIBA: UN TRABAJO COMPARADO ENTRE MIAU Y EL CORONEL NO TIENE QUIEN LE ESCRIBA
}

\author{
Mayela Vallejos Ramírez
}

\begin{abstract}
RESUMEN
En este artículo la autora realiza un análisis comparativo entre Miau, de Benito Pérez Galdós, y El coronel no tiene quien le escriba, de Gabriel García Márquez, desde el punto de vista de la estructura, el planteamiento de la temática y el comportamiento de los personajes principales.
\end{abstract}

\section{ABSTRACT}

In this article, the author makes a comparative analysis between Benito Perez Galdós' Miau and García Márquez' El coronel no tiene quien le escriba, from the perspective of structure, presentation of the main issues and development of the main characters.

La literatura es un taller donde todos aportamos nuestras fuerzas para producir lo que llamamos obra de arte.

Pablo Neruda

El escritor argentino Jorge Luis Borges consagra muchos años de su obra literaria a la exploración de la originalidad en la literatura, ya que consideraba que este trabajo era poco original. Borges concibe la literatura como algo universal, cíclico, que siempre se está repitiendo, porque la literatura es un ejercicio constante de la escritura, lo que conlleva a la reescritura del texto. Como resultado, encontramos un cierto número de obras literarias que se asemejan al compartir estilos, temas, motivs y estructuras en general. Esto ha llevado a algunos críticos a entrar en polémicas en relación con la originalidad de un texto. Un ejemplo claro fue la polémica que surgió entre las novelas Cien años de soledad de Gabriel García Márquez, publicada en 1967 y La casa de los espíritus de Isabel Allende, publicada en 1982. 
Esto nos lleva a plantearnos la pregunta ¿qué es la originalidad? El diccionario de la Real Academia define la palabra como: "Dícese de la obra científica, artística, literaria o de cualquier otro género producida directamente por su autor sin ser copia, imitación o traducción de otra." Entonces, ¿qué explicación encontramos para dos textos literarios que se asemejan y han sido escritos por dos autores y, aún más, en siglos completamente diferentes? De acuerdo con Jorge Luis Borges no hay autores legítimos, lo que realmente existen son las ideas, las cuales se encuentran dispersas por el universo. Parafraseando a Edward Water Hood, este dice que Borges en su ensayo "Kafka y sus precursores", toma como ejemplo a Kafka, a quien había considerado como un escritor originalísimo, y le busca precursores. La conclusión a la que llega Borges muestra que siempre se puede establecer una relación entre un texto y otro, entre un escritor y otro: " A éste, al principio lo pensé tan singular como el fénix de las alabanzas retóricas; a poco de frecuentarlo, creí reconocer su voz, sus hábitos en textos de diversas literaturas, de las diversas épocas" (1981: 307). Al fin de cuentas, el tiempo es cíclico, constante, infinito y recurrente: "Nada existe que no haya existido antes, y nada existirá que no exista ya. Dios hace que el pasado se repita" (Eclesiastés 3: 15).

Sin embargo, para Borges, la posibilidad de repetición exacta no puede darse en los textos. Para él, siempre la repetición resulta más hermosa que el original. Esta teoría es la que desarrolla en su cuento "Pierre Menard, autor del Quijote", en el que un texto idéntico al escrito por Miguel de Cervantes puede adquirir su propia independencia. La repetición, entonces, adquiere su originalidad en la trascendencia que lo separa del otro texto. Edward Hood (1992: 17) señala que "el original, como el significado del signo sólo existe como el rastro que queda de él en la repetición. Una palabra, una frase repetida nunca significa lo mismo, nunca se repite idénticamente dos veces", lo cual se refuerza con la idea de Heráclito: "No se entra dos veces al mismo río." La repetición siempre es un proceso creador. Podríamos considerar que dos cosas son repetidas, no porque son idénticas sino porque comparten similitudes, fenómeno que facilita el estudio de la literatura comparada, sin llegar a verse necesariamente como un proceso de intertextualidad.

Estos planteamientos nos llevan a meditar sobre los aportes que el realismo introdujo en el siglo XIX, ya que estos marcaron un cambio fundamental en la percepción de la realidad social y de sus individuos, especialmente en el campo literario. La literatura pasó a ser algo más que un medio para entretener a un determinado sector de la sociedad, para convertirse en un instrumento de crítica social. El realismo se desarrolló particularmente en Europa en donde tiene sus mayores exponentes, como el caso del escritor español Benito Pérez Galdós. Esta corriente literaria traspasa las fronteras europeas para influir en el resto del mundo literario.

En el caso particular de Latinoamérica, el realismo encontró un terreno bastante fértil. Sin embargo, este se pintó con los propios matices de una realidad sociocultural, política y económica diferente a la europea. Pero a pesar de las indiscutibles transformaciones, el realismo en Latinoamérica se ha conservado hasta el siglo XX. De ahí, que nos atrevamos a decir que el planteamiento de Carlos Fuentes sobre la existencia de "la novela latinoamericana" pueda ser modificado, diciendo que lo que existe es "la novela de habla española" porque no sólo compartimos una lengua, sino también toda una historia. De ahí, la gran pregunta de los historiadores con relación a la celebración de los quinientos años del descubrimiento: ¿quién descubrió a quién? 
Hemos hecho todos estos planteamientos para introducirnos en la lectura comparada de dos novelas: Miau de Benito Pérez Galdós y El coronel no tiene quien le escriba de Gabriel Garcia Márquez. Estas dos obras literarias, a pesar de sus diferencias temporales, nos permiten realizar una comparación gracias al número de semejanzas en lo que se refiere a estructura, planteamiento de la temática y, sobre todo, desarrollo del personaje principal en cada texto.

El primer elemento que hallamos muy importante de destacar es que El coronel no tiene quien le escriba ha sido considerada por la crítica como novela del realismo social; así lo señala Bollettino: "El realismo social ya mencionado en la primera novela ( La hojarasca) es en El coronel no tiene quien le escriba más patente y más brillante" (48). Claro está que este realismo latinoamericano difiere del europeo por llevar implícita una cuestión de tipo ideológico, como lo explica Joaquín Marco: "El coronel no tiene quien le escriba parece, a los ojos de su autor, próximo al realismo, a la literatura "comprometida"... La historia fue escrita en París en los años en que el colonialismo francés perdía lentamente su última batalla: la guerra de Argelia" (13). El mismo Gabriel García Márquez confiesa que el personaje se lo inspiró un francés que encontró una madrugada, caminando por los callejones de París:

Cuando atravesaba el puente de Saint-Michel, sentí los pasos de un hombre, vislumbré entre la niebla la chaqueta oscura, las manos en los bolsillos, el cabello acabado de peinar, y en el instante en que nos cruzamos en el puente vi su rostro óseo y pálido por una fracción de segundo: iba llorando (El olor de la Guayaba 1986: 96).

A esta imagen, García Márquez le ha agregado otra de un hombre de su Colombia natal: "Es la imagen de un hombre esperando una lancha en el mercado de Barranquilla. La esperaba con una especie de silenciosa zozobra" (1986: 35). Estas imágenes se funden con su espera de dos largos años en París y así se produce el personaje del coronel. Como podemos notar, el personaje ha emergido de una realidad social de la época: "Gabriel García Márquez arranca a sus personajes de la realidad cotidiana, de su cosmos narrativo en el que pululan viejos coroneles veteranos; médicos, dentistas y revolucionarios" (Bollettino 1973: 49).

En el caso del personaje de Pérez Galdós, Villaamil también es producto de la realidad social de la época, como señala Robert J. Weber (1964: 4):

It is fact that the "cesante" theme was a common place of the times. It appears in Fortunata y Jacinta and La de Bringas before Villaamil is one of those "cesantes" who are constantly awaiting a crisis or a new goverment in the hope that their chances of reappointment might improve.

El cesante era un tema que le atraía enormemente a Galdós, probablemente porque era uno de los grandes problemas del siglo XIX en España. Villaamil, como señala Hoyle (1991: 87), "es un prototipo social de mucho relieve". La situación era tan abrumadora para los españoles en ese periodo que, posiblemente, Pérez Galdós se encontrara a diario con cientos de Villaamiles por las calles de Madrid.

Desde este punto vista, ambas novelas reflejan un marcado realismo social que pretende desenmascarar al sistema gubernamental. Especialmente, en ambos contextos históricopolíticos, el sistema siempre estaba cambiando sus gobernantes y funcionarios públicos. De ahí la inestabilidad que se produce en la sociedad, porque al vivir en un constante cambio no 
se sabe a quién acudir. En otras palabras, el mundo se ha convertido en un caos. Esto se puede apreciar en Villaamil cuando llega a las oficinas para ver su nombramiento. Nadie sabe nada. Las personas que podían ayudarlo ya no están, y los papeles están refundidos. De la misma manera se observa con el coronel cuando va a visitar a su abogado y este le informa que probablemente algunos de sus documentos se han perdido para siempre.

Para desarrollar esta temática social, ambos escritores han estructurado sus novelas en forma lineal, con la excepción de aislados momentos en que los personajes abandonan el presente para rememorar tiempos gloriosos, como se puede apreciar con Villaamil: "Yo, en el 55 hice un plan de presupuestos que mereció los elogios del Sr. D. Pascual Madoz y del Sr. D. Juan Bruil" (15). De la misma manera, recuerda el coronel sus mejores años :

Encontró en el baúl un paraguas enorme y antiguo. Lo había ganado la mujer en una tómbola política destinada a recolectar fondos para el partido del coronel. Esa misma noche asistieron a un espectáculo al aire libre que no fue interrumpido a pesar de la lluvia. El coronel, su esposa y su hijo Agustín- que entonces tenía 8 años- presenciaron el espectáculo hasta el final sentados bajo el paraguas (53).

La narración lineal en ambas novelas se ve trenzada con otros hilos narrativos: las relaciones familiares que están impregnadas de gran conflicto socio-político y personal. Sin embargo, en este análisis las omitimos porque nuestro objetivo es la comparación de los dos personajes principales de ambos textos.

El narrador en ambas novelas es omnisciente. La única diferencia es que el narrador de El coronel no tiene quien le escriba se identifica mucho con el personaje del coronel, pero mantiene una gran objetividad a través de toda la obra; cada acontecimiento está narrado con suma sobriedad y cuidado. En el caso de Miau, el narrador participa abiertamente en un diálogo con el lector y deja notar claramente sus sentimientos hacia los personajes por medio de pequeños comentarios o focalizaciones: "-Yo me quedo un poco más- respondió el honrado, que deseaba quitarse de encima aquella calamidad" (127).

Los pequeños diálogos entre los personajes en ambas novelas ofrecen la oportunidad de conocer un poco más sus pensamientos y la relación que se da entre ellos, lo que nos permite llegar a un mejor entendimiento de la psicología de cada uno. Así por ejemplo, Abelarda profundiza en la psicología de los personajes por medio de sus comentarios.

Otro aspecto de la estructura que nos parece importante es el tratamiento que se le da al tiempo en ambas novelas. El tiempo juega un papel fundamental, ya que es el que logra humanizar al personaje central en ambas novelas. El tiempo aquí trabaja como un arma de doble filo, porque de la capacidad que tenga el personaje para jugar con él depende su salvación. El tiempo en esta novela está hecho de la espera. Entonces, se nos presenta una lucha contra el tiempo porque es un tiempo que conlleva hambre y miseria. Como señalamos anteriormente, sólo el estoicismo del personaje puede salvarlo, siendo ésta una marcada diferencia entre Villaamil y el coronel, ya que este último sí tiene la capacidad de la espera.

A medida que vamos penetrando en la narración, podemos sentir cómo la atmósfera se va volviendo más densa, tal vez porque en cierta medida ambas novelas poseen un marcado surrealismo a la hora de precisar el tiempo. Joaquín Marco en su introducción a El coronel no tiene quien le escriba indica que: 
En esta novela todo es cuestión de siglos, los zapatos tienen cuarenta años, el coronel abandona Macondo 'el miércoles veintisiete de junio de mil novecientos seis a las dos y dieciocho minutos de la tarde’. Esta precisión en el tiempo tiene un marcado carácter surrealista (21).

En el caso de Miau se especifican las fechas en que Villaamil ha desempeñado diferentes cargos o las relacionadas con sus ideas presupuestarias hasta que todo se vuelve algo obsesivo: " $¡$...Con arreglo a la ley del presupuesto del treinta y cinco, modifica la del 65 y 68 " (14). Hay, sin embargo, una diferencia importante porque el tiempo en Miau es mucho más cronológico, realista. En otras palabras más apegado a la época.

Ambos escritores han utilizado alusiones a eventos nacionales o internacionales para ubicar al lector en un tiempo determinado. En el caso de El coronel no tiene quien le escriba las noticias que lee el coronel en el periódico hacen alusión al problema del canal de Suez y en Miau se nombra la presencia de Alfonso XII y Mercedes en la ópera. En algunas ocasiones se mencionan fechas para lograr intensificar la acción:

Nació en 1922 - dijo- Exactamente un mes después de nuestro hijo. El siete de abril" (El coronel no tiene quien le escriba: 50 )

No eran las once de la mañana del día siguiente, día último del mes, por más señas, Villaamil subió con trabajo las encajonadas escaleras del ministerio" (Miau: 121).

En otras ocasiones, la mención del tiempo nos lleva a corroborar otros datos de los personajes pero en forma indirecta como es el caso de la edad de ambos protagonistas: "Desde que entró a servir allá por el 42 y cuando tenía veinticuatro años de edad... En fin que había cumplido sesenta años, y los de servicios bien sumados eran treinta y cuatro y diez meses" (Miau: 14), En el caso del coronel, se presenta cuando habla con el sirio Moisés: “- Así era antes - dijo - Si ahora fuera lo mismo yo tendría ochocientos noventa y siete años. ¿Y tú? "Sesenta y cinco" dijo el coronel" (138).

Finalmente, se hacen relaciones temporales con las estaciones del año. Sabemos que la narración en Miau comienza aproximadamente en febrero, a finales del invierno, como lo señala Lowe: "It is generally agreed that the main action of the novel takes place in the late winter (February) and early spring (May) of 1978" (472), mientras que en El coronel no tiene quien le escriba se inicia en octubre (llamado invierno en el trópico por las lluvias) y concluye a principios de diciembre cuando empieza la primavera (acaban las lluvias). Esto nos permite concluir que ambas novelas se desarrollan en un lapso de aproximadamente dos meses. Es interesante apreciar que tanto Pérez Galdós como García Márquez escogieron las estaciones que están más relacionadas con la idea de la muerte y la vida, porque con el invierno se cierra el ciclo de las estaciones y con la primavera se da paso a una nueva resurrección.

Esta idea de la conclusión y el comienzo de un ciclo, nos ofrece el camino para entrar en la temática de estas novelas. En los temas de ambas novelas precisamente se encuentran muchos aspectos en común. Sin embargo, el tratamiento que se les ha dado es lo que marca la diferencia. Podríamos decir que el personaje del coronel es mucho más fuerte que el de Villaamil. Además, el coronel es un personaje totalmente optimista: "La vida es lo mejor que se ha inventado" (112). Su grandeza radica en la capacidad que tiene para salir adelante a pesar de que su vida sea una verdadera calamidad: 


\begin{abstract}
La tragedia del viejo coronel se convierte en el análisis de lo que hace que la aventura del hombre, en Colombia o en cualquier otra parte, resulte conmovedora. Como un náufrago aferrado a una tabla, su capacidad de resistir las contrariedades parece infinita. Su esperanza es universal, como su rebeldía (Marco: 45).
\end{abstract}

El personaje del coronel es muy interesante porque es casi como un niño que puede vivir de la esperanza, como lo señala Hars (1996: 401): "Una especie de niño prodigio, envejecido, loco y cuerdo, conmovedor y humano, maravilloso y tragicómico". Mientras, el personaje de Villaamil es una mezcla entre el optimismo y el pesimismo. Esto no sólo es reflejo de su cesantía sino que es una parte de su personalidad: "En uno de sus viajes a Cuba, corriendo furioso temporal, se compenetró absolutamente en la idea de morir, arrancó de su espíritu toda esperanza y el vapor hubo de salvarse" (103). Sin embargo, la filosofía popular con la que ha gobernado su vida ("Piensa mal y acertarás") es la que lo encamina a la derrota porque en el momento en que ésta no le funciona para resolver sus problemas se le ve hundirse en un profundo y verdadero pesimismo y su vida se convierte en un laberinto sin salida.

Lo que sí tienen estos dos personajes en común es la perseverancia ortodoxa. En ese sentido, sí podemos decir que ambos son optimistas a su manera. Al coronel lo vemos persistir por quince años consecutivos. Cada viernes va al muelle a esperar su carta sin perder la fe, constancia que también caracteriza a Villaamil por un periodo de su cesantía: "Don Ramón se lanzaba otra vez, hambriento de justicia, a la oficina de personal, arrostrando desaires, malas caras y peores respuestas" (92).

Ligada a esta perseverancia podemos apreciar la dignidad que caracteriza a estos personajes que son totalmente honestos. El asistir diariamente a las oficinas para Villaamil es un martirio porque él sí sabe que no es merecedor de tanto atropello: "Villaamil era delicado, y sufría lo indecible con tales desaires; pero la imperiosa necesidad le obligaba a sacar fuerzas de flaqueza y a forrar de vaqueta la cara" (92).

La situación de Villamil es real, existe. Él es un cesante que se encuentra atrapado ante tanta burocracia que lo desestima y lo hace sentirse incapaz. Un sentimiento muy similar es el que siente el coronel cuando el administrador le dice una vez más que no hay nada para él:

El administrador no levantó la cabeza. - Nada para el coronel dijo - El coronel se sintió avergonzado. - No esperaba nada - mintió. Volvió hacia el médico la mirada enteramente infantil Yo no tengo quien me escriba (65).

Pero la perseverancia y la paciencia que caracteriza al coronel es lo que lo salva. Por eso su mujer le dice: "Se necesita tener paciencia de buey que tú tienes para esperar una carta durante quince años" (82). Mientras que el mismo Villaamil confiesa: "Con todo, a veces se retiraba consternado diciendo para su capote: ' $¡ N o$ puedo Señor, no puedo! El papel de mendigo porfiado no es para mí' "' (92).

Estos personajes son llevados hasta lo más hondo del abismo porque a todo esto se suma "el hambre". Tanto a Villaamil como al coronel los vemos tragarse el orgullo para solicitar préstamos de sus amigos. Villaamil lo hace por medio de cartas que le envía a sus amigos con su nieto Luisito. Ambos hacen promesas de pagar pronto aunque ni siquiera ellos mismos saben cuándo podrán hacerlo, como se puede observar en este pasaje: 
A él le correspondió esta vez remendar la economía doméstica. Tuvo que apretar los dientes muchas veces para solicitar crédito en las tiendas vecinas (94).

Este problema se incrementa aún más porque sus respectivas esposas piensan que sus maridos no hacen lo suficiente para cambiar la situación. La esposa del coronel, por ejemplo, le reprocha que tienen que mantener un gallo cuando ellos muchas veces se acuestan con el estómago vacío y le dice: "Y tú te estás muriendo de hambre (...) Para que te convenzas que la dignidad no se come" (117). Asimismo, ambas mujeres los critican, a la vez que les indican cómo es que deben hacer las cosas para que éstas salgan bien. Doña Pura, por ejemplo, le dice a Villaamil:

- Ya voy. Con tantos remilgos, con tantos miramientos como tú tienes, con eso de llamarles a todos dignísimos, y ser tan delicado y tan de ley que estás siempre montando al aire como los brillantes. Lo que consigues es que te tengan como cualquiera....Eres inofensivo, no muerdes, ni siquiera ladras, y todos se ríen de ti. Dicen: El empleado probo.... Yo cuando me enseñas un probo le miro para ver si tiene los codos de fuera. En fin, que te caes de honrado, a veces es como decir ñoño. Y no es eso, no es eso. Se puede tener toda la integridad que Dios manda, y ser un hombre que mire por sí y por su familia (12).

Quejas similares son las que se oyen de la esposa del coronel, porque ella sabe que él no tiene el coraje de ir a empeñar las cosas o exigir que se le haga justicia:

Lo que pasa es que a ti te falta carácter - dijo luego-. Te presentas como si fueras a pedir limosna cuando debías llegar con la cabeza levantada y llamar aparte a mi compadre y decirle: "Compadre he decidido venderle el gallo."... "No tienes el menor sentido de los negocios", dijo. "Cuando se va a vender una cosa hay que poner la misma cara con que se va a comprar." Te estoy hablando en serio - dijo" (123).

No podemos recriminar la actitud de estas mujeres porque realmente están cansadas de llevar casi a solas las penurias y pobrezas del hogar. Si observamos detenidamente podremos comprobar que sus esposos viven más bien la vida como en un sueño. La crítica ha encontrado la actitud del coronel un tanto quijotesca y podemos decir que esas mismas actitudes quijotescas exhibe Villaamil. Por eso se pueden sentir un poco fuera de la realidad, porque fundan sus esperanzas en las glorias pasadas, ya que lo que realmente poseen es la dignidad histórica heredada del pasado. En ese sentido sus mujeres son más realistas y son las que resuelven el hambre inmediata. Esto se puede apreciar claramente con el comentario que le hace Villaamil a su cuñada cuando ésta le pregunta si van a cocinar sancocho: "Esperemos a que se levante Pura. Ella era la que resolvía todos los conflictos, como persona de iniciativa, de inesperados golpes y de prontas resoluciones" (19).

Por eso, el narrador dice: "tiempo hacía que estaba resignado a que su señora llevara los pantalones en la casa" (42). Esta misma actitud casi de maga es la que tiene la esposa del coronel: "Con su asombrosa habilidad para componer, zurcir y remendar, ella parecía haber descubierto la clave para sostener la economía doméstica en el vacío" (77). La mayor diferencia que podemos apreciar entre las dos mujeres es que doña Pura vive más de las apariencias. Vive al día como dice el narrador y no piensa nunca en el mañana. Entonces, cuando tiene un poco de dinero, lo despilfarra sin medir futuras consecuencias. Mientras, se puede apreciar que la mujer del coronel es más comedida y lo único que realmente desea es una vida menos angustiosa. 
Esto nos lleva al tema del nivel de las apariencias que es latente en ambos textos. El símbolo que se utiliza para mostrar un cierto estatus lo vemos representado en "la sala" de ambas casas. Se puede apreciar que la sala es el sitio más elegante de la familia Villaamil. Además, que es el orgullo de doña Pura porque ahí puede sentirse como en los viejos tiempos. Sólo el hecho de pensar en empeñar algún mueble y sobre todo las cortinas, trastorna a doña Pura:

¡La sala, hipotecar algo de la sala! Esta idea causaba siempre terror y escalofríos a doña Pura,
porque la sala era parte del menaje que a su corazón interesaba más, la verdadera expresión
simbólica del hogar doméstico. Poseía muebles bonitos, aunque algo antiguos, testigos del pa-
sado esplendor de la familia Villaamil (17).

La sala como espejo exterior de la situación del hogar no puede desaparecer. Es el sitio donde llegan los amigos y si no ven alguno de los muebles, como dice doña Pura, qué van a comentar. El qué dirán es importantísimo en esta novela. Hay que guardar las apariencias a toda costa. Este mismo concepto lo vemos en El coronel no tiene quien le escriba:

A diferencia del dormitorio, demasiado estrecho para la respiración de una asmática, la sala era amplia, con cuatro mecedoras de fibra en torno a una mesita con un tapete y un gato de yeso. En la pared opuesta a la del reloj, el cuadro de una mujer entre tules rodeada de amorines en una barca cargada de rosas (51).

Sin embargo, cuando la situación llega a los máximos extremos, la esposa del coronel no tiene reparos para tratar de vender lo poco que les queda de valor y que precisamente está en la sala.

En contraste con la sala, nos encontramos con la cocina, que es el verdadero aposento que muestra la situación real de las familias. La imagen que resalta de ambas cocinas es la miseria. Cuando Villaamil llegó a la cocina, "examinó el fogón sin lumbre, la carbonera exhausta; y en la alacena que hacía de despensa vio mendrugos de pan..." (18). Esta misma sensación de miseria es la que se siente cuando el coronel comprueba que no queda nada para el desayuno: "El coronel destapó el tarro del café y comprobó que no había más que una cucharadita" (49). Esta escena además de mostrarnos la miseria que están pasando estas familias sirve para resaltar la calidad humana en cada uno de ellos. Villaamil al comprobar que sólo existe una barrita de chocolate dice a su cuñada: "A mí no. Lo haces para el niño. Yo no necesito chocolate" (19). Acto similar de amor tiene el coronel para con su mujer cuando le dice: "¿YY tú? - dijo- Ya tomé - mintió el coronel -. Todavía quedaba una cucharada grande" (50).

Retomando el tema de las apariencias, la cocina juega un papel clave porque se puede observar cómo estas esposas tratan de guardar las apariencias a través de sus cocinas. Por una parte, doña Pura sigue invitando a sus amigos y preparando festines en la cocina para que piensen que su situación no es mala como ellos creen. Y por otra parte, la esposa del coronel pone a cocinar piedras para guardar las apariencias: "Varias veces he puesto a hervir piedras para que los vecinos no sepan que tenemos muchos días de no poner la olla" (116).

Esta miseria económica nos lleva a una miseria aun más letal que es la miseria física y espiritual. Tanto Villaamil como el coronel están viejos, cansados y enfermos. Villaamil es descrito como un tigre decadente y tísico y el coronel tiene todo el estómago lleno de hongos 
y lirios venenosos. Se ven imágenes semejantes de ambos personajes: "Villaamil, solo, insomne y calenturiento, se revolcaba en el gran camastro matrimonial" (18) y al coronel lo vemos metido en su hamaca: "Un hilo de sudor helado resbaló por su columna vertebral. Tenía fiebre. Se sintió flotando en un círculo de gelatina" (68). El mundo que los rodea está, como ellos, desmoronándose y pudriéndose; como dice la esposa del coronel: "Todo está así (...) Nos estamos pudriendo vivos" (53). Las enfermedades y la muerte son parte de la atmósfera que rodea a ambos personajes. A todo esto hay que añadir la pérdida de sus hijos. Villaamil perdió a su hija Luisa cuando ésta perdió la cordura por el calavera de su marido; en el caso del coronel, su hijo Agustín fue asesinado por pertenecer a un grupo clandestino opositor al gobierno. En ambas historias, la pérdida de los hijos causó un deterioro moral y espiritual en los personajes: "El buen Villaamil, que, sin ruidoso duelo exterior, mudo y con los ojos casi secos, se desquició y desplomó interiormente, quedándose como ruina lamentable, sin esperanzas, sin ilusión ninguna de la vida" (46). En el caso del coronel no se describen abiertamente sus sentimientos pero podemos inferir que ha sido un golpe duro para la pareja por lo que expresa la esposa del coronel: "somos huérfanos." Lo que sí podemos plantear es la razón por la cual el coronel conserva el gallo a costa de lo que sea. Este animal es lo único que le queda de su hijo. En cierta medida, es el mismo sentimiento que profesa Villaamil por Luisito. Una vez más, podemos observar una diferencia básica entre estos dos personajes. El coronel, al final, decide conservar el gallo aunque tenga que seguir pasando hambre, pero Villaamil se deja atrapar por el derrotismo, le entrega a Luisito a su tía y, ya sin esperanza, se suicida.

Para abordar el tema del suicidio, manejamos tres conceptos: el enemigo oculto, la soledad y la toma de conciencia. Comenzaremos por la idea de que en ambas novelas hay un "enemigo oculto". En el caso de Villaamil, ese enemigo es su yerno, como lo señala Alan Hoyle (1991: 90): "No se trata de simple manía persecutoria; de hecho sí hay alguien que mete la baza para impedir que Villaamil consiga colocarse de nuevo. Este alguien es Víctor. No lo vemos maniobrar pero según Pantoja, Víctor ha dicho al diputado disidente que se ofrecía a apoyar a Villaamil que este está demasiado loco para desempeñar ningún cargo".

Diferimos con Hoyle porque sí vemos maniobrar a Víctor por medio de sus monólogos interiores en donde deja esclarecido el odio que siente. Víctor es un ser egoísta, repulsivo y sin escrúpulos que se solaza criticando y burlándose de Villaamil y de su familia. "La diferencia moral entre el honrado Villaamil y el sinvergüenza de su yerno queda destacada tanto en la novela como en la crítica" (Hoyle 1991: 90). En El coronel no tiene quien le escriba también nos encontramos con un "enemigo oculto": don Sabas. Es un comerciante sin escrúpulos que es capaz de cualquier cosa para mantener el estatus económico que ha adquirido. Bollettino considera que "Don Sabas contribuye a la derrota del coronel privándole de su necesidades diarias. En el mundo de García Márquez, los pobres están inexorablemente condenados a la destrucción, especialmente en pueblos aislados cuya vida y desarrollo político y social lo determinan unos pocos individuos" (59). Es interesante leer que Bellini (1983: 210) también hace una comparación entre estos dos personajes para mostrar la falta de escrúpulos de Don Sabas:

Il mutamento avvenuto nella struttura sociale del villaggio è reso da García Márquez nel confronto fisico e morale tra i due personaggi, el corolonnello e don Sabas: magro il primo, debilitato dalla fame; grasso,be pasciuto il secondo, fornito di un'abbondanza di beni persino superflua che, caratteristico dettaglio, accumula nel disordine proprio dell'abbondanza. 
El factor dinero es el que va a jugar un papel básico en esta relación Villaamil - Víctor y el coronel - don Sabas. Si bien es cierto quie Villaamil no desea aceptar el dinero de Víctor, su mujer lo convence porque el hambre es más poderosa. Entonces, cae en poder de Víctor. Villaamil se siente humillado porque tiene que aceptar que depende de este ser indeseable y corrupto. El coronel, por su parte, cansado de los reproches de su mujer y tentado por los novecientos pesos que dice don Sabas que vale el gallo decide ir a vendérselo. Este le ofrece en esa segunda ocasión solo la mitad y, al darle un adelanto de sesenta pesos, el coronel, como Villaamil, se encuentra atrapado en las redeş de este hombre. Pero la diferencia está en que el coronel tiene amigos verdaderos, como el médico, que le hacen tomar conciencia de su realidad social y del tipo de individuo que es don Sabas: "El único animal que se alimenta de carne humana es don Sabas -dijo el médico-. Estoy seguro que lo revenderá por los novecientos pesos"(130). De ahí en adelante, el coronel empieza a ver la realidad de su mundo. El mundo realmente no es como él se lo había imaginado, y él no tiene derecho a quitarle la última esperanza que tiene el pueblo puesto en ese gallo. Por eso, decide que aunque tengan que comer "mierda" el gallo no se vende, como lo sustentan las palabras de Bollettino (1973: 61):

Toda su vida no fue sino un intento desesperado de no enfrentar la realidad refugiándose ya en su orgullo militar, ya en su pensión de veterano, ya en su gallo de pelea, pero todo en vano. Por lo menos ahora no tiene que esconder que la vida es "una mierda". El coronel enfrenta la realidad con violencia, sin recurrir al suicidio (61).

Por su parte, Villaamil tiene una reacción muy diferente al comprobar que está solo, que su relación familiar es inexistente y que los supuestos amigos lo abandonan y se burlan de él. Se compra una pistola porque ya no tiene más fuerzas para seguir luchando. Se siente como un Cristo abandonado y camino al calvario. Todo ha desaparecido con la pérdida de la fe, como lo expresa Penuel (1987: 87): "Villaamil placed all his faith in the bureaucracy. When he lost that faith there was nothing left for him but death". Estamos de acuerdo con Penuel en que realmente no es la injusticia ni la desigualdad la que va a marcar una pauta decisiva en la vida de los individuos: es realmente el carácter de la persona lo que va a labrar el destino, porque lo que se está mostrando en estas obras es la reacción que tienen las personas para enfrentar sus problemas. En otras palabras, se desarrolla un fuerte nexo entre el carácter del individuo y el contexto circunstancial. Ambos personajes se ven atrapados, manipulados por su medio y por las relaciones con personajes que en cierta medida sabotean una situación propicia. Pero al final podemos observar dos reacciones totalmente diferentes de estos dos personajes para enfrentar las injusticias sociales.

Finalmente, queremos decir que en las novelas la vida humana se ha reducido a la condición de animales. En ambas, los personajes se comparan con animales para proyectar en cierta medida lo tragicómico de cada uno de ellos. En el caso del coronel, él mismo dice que debe verse como un "papagayo," con el pelo parado y con la ropa ridícula y pasada de moda que tiene que usar para ir al cementerio. Su mujer también lo compara con la resistencia que tienen los "bueyes" para soportar la espera. Entonces, tenemos la imagen de un pájaro un tanto cómico, y la fortaleza y paciencia de un buey. El coronel a su vez piensa que su mujer parece un "pájaro carpintero," con el traje de tantos colores que se ha fabricado, lo cual también viene a reforzar la imagen de una mujer que es hábil y creativa. Finalmente, se comparan los ojos de don Sabas con los de un sapo, ya que este anfibio siempre está al acecho de sus presas. 
La idea de los felinos en Miau es, por supuesto, evidente. Villaamil es comparado con un "tigre tísico" y con un "lobo en ayunas". Ya Villaamil no tiene salvación: su vida muestra un completo deterioro físico y mental, mientras que las Villaamil son felinas un tanto ridículas, grotescas y hasta un tanto esperpénticas, interesadas la mayor parte del tiempo en actividades sociales donde poder lucirse. De vez en cuando, doña Pura sale a cazar algo y, con la audacia que caracteriza al gatuno, siempre encuentra algo. Por eso Villaamil se compadece de Ponce que ha caído en las garras de las tres "Miaus". Sin lugar a dudas, el naturalismo aquí juega un papel esencial, mientras que en El coronel no tiene quien le escriba se presenta más bien una especie de anti-naturalismo: "La determinación de los personajes' de no sucumbir a las fuerzas de podredumbre añade gran heroísmo a las figuras humanas... Esta es una clave del antinaturalismo. Los personajes aún sabiéndose vencidos no se sienten vencidos" (Bollettino 1973: 50). En fin, la técnica es muy efectiva en ambas novelas porque reduce al personaje para contrastarlo con lo adverso del mundo que los rodea

Para concluir, nos llama la atención sobre manera la universalidad de la temática usada en ambas novelas. De ahí, la posibilidad de compararlas aunque pertenezcan a dos periodos y dos culturas diferentes y similares a la vez. En todas las épocas, las sociedades han padecido los mismos problemas sociales. Estos sistemas aparecen y desaparecen siempre como para mantener un ciclo universal.

\section{Bibliografía}

Bellini, Giuseppe. 1983. "El coronel no tiene quien le escriba o il riti della miseria." Studi di Letteratura Ispano-Americana (15-16): 203-15.

Bollettino, Vicenzo. 1973. Breve estudio de la novelística de García Márquez. Madrid: Playor S.A.

Borges, Jorge Luis. 1981. Ficcionario: una antología de sus textos. Emer Rodríguez Monegal (Ed.). México D.F.: Fondo de Cultura Económico.

Calsaduero, Joaquín. 1982. "La crítica literaria y socioeconómica galdosiana." Hispania. 390 (Dec): $535-44$.

Crispin, John. 1982. "The Role of Secondary Plots and Secondary Characters in Galdo's Miau." Hispania. 65 (Sep): 365-70.

Derrida, Jacques. 1978. Writing and Differences. Tras. Alan Bass. Chicago: The University of Chicago Press.

Fiddian, Robin W. 1985. "Two Aspects of Techniques in El coronel no tiene quien le escriba." Neophilologus. 65 (July): 388-93.

Fuentes, Carlos. 1972. La nueva novela Hispanoamericana. México D.F.: Joaquín Mortiz. 
García Márquez, Gabriel. 1986. El coronel no tiene quien le escriba. Madrid: Espasa-Calpe, S.A.

García Márquez, Gabriel y Plinio Apuleyo Mendoza. 1986. El olor de la guayaba. Bogotá: La Oveja Negra.

Gutiérrez Muat, Ricardo. 1982. "The Economy of the Narrative Sign in the Novel No one writes to the Colonel." Gabriel García Márquez and the Powers of Fiction. Ed. Julio Ortega. Austin: University of Texas Press: 17-33.

Hars, Luis. 1966. “Gabriel García Márquez o la cuerda floja.” Los nuestros. Buenos Aires: Suramericana.

Hood, Edward. 1992. La ficción de Gabriel García Márquez: repetición en intertextualidad. Diss. University of California. San Diego: Privately printed.

Hoyle, Alan. 1991. "El transfondo irónico y económico de Miau". Revista de Literatura. 53 (Jan-June): 85-102.

Lowe, Jennifer. 1988. "Villaamil's Two Months: A Study of Time in Pérez Galdós Miau." Neohiologus. 72 (July): 472-74.

Marco, Joaquín. Introducción. 1986. El coronel no tiene quien le escriba. Por Gabriel García Márquez. Madrid: Espasa-Calpe, S.A.

Miller, J. Hills. 1982. Fiction and Repetition: Seven English Novels. Cambridge: Harvard University Press.

Penuel, Arnold M. 1987. "Yet another View of Miau." Psychology and Ethics in Galdo's The Quest for Authenticity. Lanham: University Press of America.

Pérez Galdós, Benito. 1989. Miau. México D.F: Editorial Porrúa, S.A.

Socha, Donald. 1990. “A Semiotic Interpretation of García Marquez's No One writes to the Colonel”. Hispanofilia. 98 (Enero): 87-95.

Weber, Robert J. 1964. The Miau Manuscript of Benito Pérez Galdós: A Critical Study. Berkerly: University of California Press. 